\title{
Pola Komunikasi Organisasi Karyawan Start Up PT. Exaditama Teknologi Kreativa Melalui Media Teknologi Komunikasi “ Slack
}

\author{
Yudha Irawan Kusdinar, Nela Widiastuti \\ Universitas ARS \\ Fakultas Komunikasi (Public Relation) \\ Email: Kyyudhairawan@gmail.com
}

\begin{abstract}
ABSTRAK
Penelitian ini mengemukakan tentang bagaimana pola komunikasi organisasi dari karyawan di PT. Exaditama Teknologi Kreativa melalu media komunikasi "Slack". Terdapat tujuan dari penelitian ini untuk mengetahui bagaimana pola komunikasi dari pimpinan PT. Exaditama Teknologi Kreativa kepada bawahanya melalui media komunikasi "Slack". Dalam penelitian ini peneliti menggunakan metode penelitian kualitatif dengan pendekatan studi kasus. Teknik pengumpulan data yang dilakukan dengan cara observasi, wawancara dan dokumentasi. Informan dari penelitian ini terdiri dari dua informan kunci dan dua informan tambahan, dua informan kunci ini merupakan dua orang pimpinan atau "Project Manager" dan dua orang tambahan ini merupakan karyawan dari PT. Exaditama Teknologi Kreativa. Hasil dari penelitian ini menjelaskan bahwa pimpinan PT. Exaditama Teknologi Kreativa menggunakan pola komunikasi roda dengan jaringan atau alur komunikasi Downward dan Upward, artinya pimpinan dari perusahaan PT. Exaditama Teknologi Kreativa menjadi pusat dari segala pesan, perintah dan arahan terhadap karyawan atau staffnya dengan berkomunikasi melalui media komunikasi "Slack". Pendapat untuk penelitian ini, lebih diutamakan kembali diskusi baik secara langsung ataupun menggunakan media teknologi komunikasi, sebab jika peningkatan komunikasi didalam organisasi sangat tinggi, maka produktifitas dan efektifitas yang terjadi dalam organisasi akan berjalan dengan baik.
\end{abstract}

Kata Kunci: Pola Komunikasi, Organisasi, Media Teknologi Komunikasi

\section{ABSTRACT}

This study presents how the organizational communication patterns of employees at PT. Exaditama Teknologi Kreativa through "Slack" communication media. Regarding the purpose of this study to find out how the communication patterns of the leadership of PT. Exaditama Teknologi Kreativa for her subordinates through the communication media "Slack". In this study, researchers used qualitative research methods by studying case studies. Data collection techniques are done through observation, interviews, and documentation. The informants of this study consisted of two key informants and two additional informants, these two key informants were two leaders or "Project Managers" and these two additional people were employees of PT. Exaditama Kreativa Technology. The results of this study explain the leadership of PT. 
Jurnal Teknologi Informasi dan Komunikasi, ISSN : 2087-0868, Volume 11, Nomor 2, September 2020, POLA KOMUNIKASI ORGANISASI KARYAWAN START UP PT.EXADITAMA TEKNOLOGI KREATIVA MELALUI MEDIA TEKNOLOGI KOMUNIKASI "SLACK"

Exaditama Teknologi Kreativa uses a wheel communication pattern with Downward and Upward communication networks or lines, connecting the leaders of the company PT. Exaditama Teknologi Kreativa is the center of all messages, orders, and direction for employees or staff by communicating through the "Slack" communication media. Opinions for this research, preferably back to the discussion either directly or using communication media, the reason if the increase in communication in the organization is very high, then the productivity and effectiveness that occurs in the organization will run well.

Keywords: Communication Patterns, Organizations, Media Communication Technology

\section{PENDAHULUAN}

Indonesia kini merupakan negara yang memiliki perusahaan startup yang berhasil menjadi startup tingkat "Decacorn", selain itu juga pada tahun 2019 Indonesia menjadi salah satu negara pencetak startup terbanyak di dunia setelah Amerika Serikat, India, Inggris, Kanada (Fadilla, 2020). Dengan peningkatannya startup di Indonesia membuat lapangan pekerjaan menjadi lebih luas khususnya dibidang teknologi. Hal tersebut disebabkan oleh pesatnya perkembangan teknologi di zaman ini.

Pesatnya kemajuannya teknologi di Indonesia saat ini, mampu membuat perkembangan teknologi komunikasi Indonesia menjadi lebih efektif dan efisien. Menurut media (DSResearch, 2020) terbukti hingga tahun 2019 Indonesia telah miliki ribuan startup dengan 1 decacorn, 6 unicorn, dan 27 centaur. Akan tetapi, sayangnya banyak perusahaan yang tidak begitu transparan dalam membuka "the company's bigger picture." Menurut survei yang dilakukan Gallup, lebih dari 3 ribu pekerja dari berbagai perusahaan hanya $41 \%$ diantaranya yang mengungkapkan pekerja mengerti "bigger picture" dari perusahaan mereka dan apa yang membedakan pekerja di perusahaan tersebut dengan yang lainnya (Nabila, 2016). Tidak hanya itu, didalam artikel "Daily Social id" ada penulis memaparkan bahwa ada beberapa kesalahan perushaaan startup yang dapat kehilangan karyawannya salah satunya adalah 
Jurnal Teknologi Informasi dan Komunikasi, ISSN : 2087-0868, Volume 11, Nomor 2, September 2020, POLA KOMUNIKASI ORGANISASI KARYAWAN START UP PT.EXADITAMA TEKNOLOGI KREATIVA MELALUI MEDIA TEKNOLOGI KOMUNIKASI "SLACK"

lingkungan yang negatif (Priambada, 2015).

Hal tersbut dapat menurunkan efisien dan efektifitas dalam sistem kerja perusahaan, khususnya dalam proses komunikasi antara bawahan dan atasan. Dengan adanya teknologi komunikasi, tidak sedikit perusahaan yang membutuhkan media komunikasi untuk kelancaran pekerjaannya agar tetap efisien dan efektif. Banyak sekali di Indonesia perusahaanperusahaan yang menggunakan media teknologi komunikasi, salah satunya adalah media teknologi “ Slack “

“ Slack “ yang kini sudah memasuki perkantoran di Indonesia, menjadikan " Slack “ sebagai salah satu media teknologi komunikasi yang sangat berguna dan bermanfaat bagi beberapa perusahaan. Selain itu juga " Slack “ menempatkan dirinya sebagai media teknologi komunikasi yang mudah untuk dipergunakan.

Banyak sekali perusahaan yang ingin sistem pekerjaannya berjalan dengan lancar atau para karyawannya bekerja secara efektif dan efisien. Salah satunya adalah PT. Exaditama Teknologi Kreativa . PT. Exaditama Teknologi Kreativa merupakan salah satu perusahaan startup dibidang teknologi aplikasi software yang sedang bergelut di kota Bandung dengan jumlah total karyawan 28 orang. PT. Exaditama Teknologi Kreativa juga salah satu perusahaan startup yang menerapkan komunikasi organisasi melalui media teknologi komunikasi. PT. Exaditama Teknologi Kreativa pun menggunakan media teknologi komunikasi, dimana media teknologi komunikasi berperan penting didalam perusahaan PT. Exaditama Teknologi Kreativa guna untuk melancarkan komunikasi antara atasan dan bawahan maupun antara karyawan itu sendiri.

Di PT. Exaditama Teknologi Kreativa media teknologi komunikasi sangatlah dipergunakan dengan baik. Media teknologi komunikasi yang digunakan PT. Exaditama Teknologi Kreativa untuk memberi pesan informasi atau tugas pekerjaan ialah "Slack". Slack dipergunakan oleh para karyawan PT. Exaditama Teknologi Kreativa 
Jurnal Teknologi Informasi dan Komunikasi, ISSN : 2087-0868, Volume 11, Nomor 2, September 2020, POLA KOMUNIKASI ORGANISASI KARYAWAN START UP PT.EXADITAMA TEKNOLOGI KREATIVA MELALUI MEDIA TEKNOLOGI KOMUNIKASI "SLACK"

mulai dari awal tahun 2020 dan hingga saat ini masih menggunakan media teknologi komunikasi berbasis aplikasi tersebut. Komunikasi tersbut biasa terjalin antara atasan dan bawahan atau pun antara karyawan sendiri. Atasan disini yang terkait dalam pengerjaan projek dengan posisi sebagai "Project Manager" diantaranya Arief Rachman, Agung Budhi serta karyawan yang dibawah naungan "Project Manager". Selain itu juga terdapat beberapa karyawan yang menjadi responden dari penelitian ini, diantaranya Reynaldi Prayuda, Luki.

\section{Para "Project Manager"} menyarankan kepada bawahannya untuk menggunakan aplikasi "Slack". "Project Manage" memiliki tujuan mengapa bawahanya menggunakan aplikasi "Slack" sebagai media komunikasinya, sebab aplikasi "Slack" menurut para "Project Manager “ dapat memudahkan dan melancarkan penyampaian pesan dengan cepat. Para "Project Manager" menyarankan tersbut juga agar dapat memanfaatkan internet serta tidak adanya kekeliruan dalam penyampaian pesan. Selain itu dengan banyaknya perusahaan yang gagal maju disebabkan kurang solidnya team atau pola komunikasi yang kurang baik didalam perusahaan, para "Project Manager" pun takut akan adanya hal negative seperti itu. Maka dari itu "Project Manager" membuat system kerja yang menurutnya cukup efektif dan efisien tetapi tetap terjaga pola komunikasinya dengan baik. Oleh karena itu perlu pendekatan yang cukup jelas anatar atasan dan bawahan atau pun antara karyawan itu sendiri yang dilihat dari komunikasinya.

Dengan adanya hal seperti ini, peneliti berfokus terhadap pola komunikasi yang diterapkan oleh PT. Exaditama Teknologi Kreativa baik dari komuikasi atsan kepada bawahan atau pun antara karaywan. Peran komunikasi organisasi di PT. Exaditama Teknologi Kreativa sangatlah penting untuk menjalin hubungan komunikasi yang baik dimana komunikasi organisasi yang baik memberikan hasil yang positif demi tercapainya tujuan bersama. Oleh karena itu komunikasi yang 
Jurnal Teknologi Informasi dan Komunikasi, ISSN : 2087-0868, Volume 11, Nomor 2, September 2020, POLA KOMUNIKASI ORGANISASI KARYAWAN START UP PT.EXADITAMA TEKNOLOGI KREATIVA MELALUI MEDIA TEKNOLOGI KOMUNIKASI "SLACK"

baik didalam organisasi akan menghasilkan sebuah proses kerja yang efektif ataupun efisien, karena dengan adanya efektif dan efisiennya komunikasi yang berada di sebuah organisasi itu sangat penting. Seperti yang sudah dijelaskan diatas bahwa komunikasi yang terdapat di organisasi dapat menciptakan dan menukar pesan satu sama lain. Ditambah dengan perkembangan teknologi, komunikasi pun dapat menjadi lebih efektif dan efisien dengan kehadirannya media teknologi komunikasi.

Oleh sebab itu peneliti bermaksud untuk meneliti ini di kareanakan peneliti tertarik untuk meneliti dari pola komunikasi organisasi yang berada disebuah perusahaan dengan obejk kajian penelitian. Dalam penelitian ini peneliti menggunakan metode penelitian kualitatif dengan jenis pendekatan penelitian studi kasus. Alasan peneliti ingin menggunakan studi kasus dikarenakan peneliti ingin lebih jelas mengetahui informasi, permasalahan dan seperti apa situasi permasalahan yang terjadi. Peneliti juga menggunakan
Teori Komunikasi Organisasi yaitu Teori Klasik dengan pengambilan Teori Klasik Manajemen Ilmiah. Peneliti menggunakan teori Manajemen Ilmiah dikarenakan ingin lebih memahami pola yang komunikasi organisasi di PT. Exaditama Teknologi Kreativa dengan didasari prinsip seperti pembagian pekerjaan, tanggung jawab, kesatuan arah, minat karyawan, perintah, kesamaan, sentralisasi dan inisiatif. Berhubungan dengan hal ini peneliti bermaksud untuk melakukan penelitian dengan judulu "Pola Komunikasi Organisasi Karyawan Start Up PT.Exaditama Teknologi Kreativa Melalui Media Teknologi Komunikasi "Slack"

Seluruh manusia dimuka bumi ini, tidak ada manusia yang tidak berkomunikasi baik komunikasi verbal maupun non verbal. Pada dasarnya manusia bisa bertahan hidup dengan menggunakan komunikasi. Peranan komunikasi sangatlah penting demi kelangsungan hidup manusia. Manusia membutuhkan lawan komunikasi untuk menyampaikan pesan kepada 
Jurnal Teknologi Informasi dan Komunikasi, ISSN : 2087-0868, Volume 11, Nomor 2, September 2020, POLA KOMUNIKASI ORGANISASI KARYAWAN START UP PT.EXADITAMA TEKNOLOGI KREATIVA MELALUI MEDIA TEKNOLOGI KOMUNIKASI "SLACK"

lawannya serta dapat menimbulkan feedback yang baik. Beberapa definisi yang sesuai dengan konsep ini sebagi berikut.

Menurut Hovland, Janis dan Kelley, “ Komunikasi adalah proses individu mengirim stimulus yang biasanya dalam bentuk verbal untuk mengubah tingkah laku orang lain “ (Muhammad, 2015).

Definisi berikutnya menurut Forsdale, “ Komunikasi adalah suatu proses memberikan signal menurut aturan tertentu, sehingga dengan cara ini suatu sistem dapat didirikan, dipelihara, dan diubah" (Muhammad, 2015).

Sedangkan menurut Brent D. Ruben, “ Komunikasi manusia adalah suatu proses mana individu dalam hubungannya, dalam kelompok, dalam organisasi, dan dalam masyarakat menciptakan, mengirimkan, dan menggunakan informasi untuk mengkoordinasi lingkungannya dan orang lain". (Muhammad, 2015).

\section{METODE PENELITIAN}

Penelitian ini menggunakan metode penelitian kualitatif. Dalam penelitian kualitatif umumnya lebih bertujuan untuk memahami, sikap dan pendapat orang atau sekelompok orang.

Penelitian ini menggunakan metode penelitian kualitatif dikarenakan peneliti berpikir bahwa permasalahan yang diangkat cukup kompleks. Untuk mendapatkan data infromasi yang cukup mendetail, peneliti melakukan metode wawancara langsung terhadap responden atau infroman.

Sumber data ini terdapat dari subjek penelitian. Subjek penelitian merupakan narasumber atau responden yang memberikan data informasi yang terakit mengenai hubungan dengan penelitian masalah. Dalam penelitian ini sumber data yang digunakan adalah dua sumber data primer dan sumber data sekunder.

Sumber data primer merupakan sumber data yang diperoleh langsung dari subjek atau responden penelitian yang merupakan karyawan dari PT. Exaditama Teknologi Kreativa dimana diantaranya merupakan “ Project Manager " dan beberapa responden tambahan yaitu karyawan staff, yang dihasilkan dari wawancara mendalam. 
Jurnal Teknologi Informasi dan Komunikasi, ISSN : 2087-0868, Volume 11, Nomor 2, September 2020, POLA KOMUNIKASI ORGANISASI KARYAWAN START UP PT.EXADITAMA TEKNOLOGI KREATIVA MELALUI MEDIA TEKNOLOGI KOMUNIKASI "SLACK"

Sumber data skunder merupakan data yang sudah ada dan diperoleh dari sumber data PT. Exaditama Teknologi Kreativa seperti catatan, dokumentasi, publikasi, struktur organisasi dan lain sabagainya. Data ini sebagi data pendukung dalam penelitian. Objek penelitian atau titik pusat dari penelitian ini adalah bagaimana pola komunikasi yang terdapat di PT. Exaditama Teknologi Kreativa. Lokasi dari penelitian ini dilakukan di PT. Exaditama Teknologi Kreativa Jalan Setrasari Kulon V nomor 6 Bandung. Penelitian ini dilakukan pada tanggal Maret - Agustus 2020.

Dalam penelitian ini, metode pengumpulan data menggunakan beberapa metode seperti wawancara, observasi dan dokumentasi.

Observasi yang digunakan oleh peneliti adalah observasi berperan (participant observation). Alasan peneliti menggunakan participant observation dikarenakan peneliti ingin mencoba lebih menggali data - data yang akan diteliti serta peneliti juga ikut terlibat dalam lingkungan. Catatan mengenai sebuah objek yang diobservasi, dari metode ini dapat diperoleh pola prilaku yang sebenarnya (Indrawati, 2018). Observasi merupakan teknik pengumpulan data dari sumber yang berupa tempat, aktivitas, benda atau rekaman gambar. Ada dua jenis observasi berdasarkan proses pelaksanaannya yaitu Observasi berperan ( participant observation) dan Observasi tidak berperan ( non participant observation) (Nugrahani, 2014).

Observasi yang digunakan oleh peneliti adalah observasi berperan (participant observation). Alasan peneliti menggunakan participant observation dikarenakan peneliti ingin mencoba lebih menggali data data yang akan diteliti serta peneliti juga ikut terlibat dalam lingkungan.

Reduksi data memfokuskan hasil dari wawancara, pengumpulan data data yang akan diseleksi untuk dijadikan informasi dalam penelitian komunikasi organisasi di PT. Exaditama Teknolgi Kreativa.

Dalam penelitian ini peneliti menggunakan teknik atau cara untuk mendapatkan validitas dengan menggunakan teknik Triangulasi. 
Jurnal Teknologi Informasi dan Komunikasi, ISSN : 2087-0868, Volume 11, Nomor 2, September 2020, POLA KOMUNIKASI ORGANISASI KARYAWAN START UP PT.EXADITAMA TEKNOLOGI KREATIVA MELALUI MEDIA TEKNOLOGI KOMUNIKASI "SLACK"

Teriangulasi merupakan teknik atau cara pemeriksaan keabsahan data dengan memanfaatkan sesuatu yang lain diluar data tersebut untuk keperluan pengecekan atau pembanding terhadap data informasi yang berkaitan langsung.

Beberapa teknik Triangulasi sumber data yang dilakukan oleh peneliti dalam penelitian mengetahui pola komunikasi organisasi PT. Exaditama Teknologi Kreativa dengan menggunakan media teknologi komunikasi " Slack " yaitu Triangulasi sumber, teknik dan waktu.

\section{HASIL DAN PEMBAHASAN}

Pola komunikasi antara atasan dan bawahan di PT. Exaditama Teknologi Kreativa melalui media teknologi komunikasi “ Slack “ Jaringan komunikasi Downward merupakan jaringan alur pesan dari seorang pimpinan terhadap karyawan. Pesan yang dimaksud merupakan pesan yang berhubungan dengan pekerjaan dalam organisasi untuk mencapai sebuah tujuan dari visi dan misi. Pesan tersbut biasanya berisi mengenai pengaruh, tujuan, disiplin, perintah, pertanyaan dan kebijaksanaan umum.

PT. Exaditama Teknologi Kreativa menerapkan jaringan komunikasi downward atau komunikasi arahan dari pimpinan kepada karyawannya. Terdapat tipe komunikasi downward sebagai berikut :

Intruksi Tugas, pesan yang disampaikan kepada bawahan mengenai apa yang diharapkan dilakukan mereka dan berbagaimana melakukannya (Muhammad, 2015). Informan Arief (P1) dan Infroman Agung (P2) melakukan intruksi tugas melalui aplikasi slack dan pemebrian tugasnya secara bertahap dalam proses penyampaiannya seperti tahap awal memebrikan tugas melalui aplikasi Trello, kemudian diskusi melalui metode scrum, lalu pemebrian tugas utamanya melalui aplikasi slack.

Informasi, dalam tipe informasi ini dimaksud untuk memperkenalkan kepada bawahan dengan praktik praktik organisasi, peraturan peraturan organisasi, keuntungan, kebiasaan, dan data yang tidak 
Jurnal Teknologi Informasi dan Komunikasi, ISSN : 2087-0868, Volume 11, Nomor 2, September 2020, POLA KOMUNIKASI ORGANISASI KARYAWAN START UP PT.EXADITAMA TEKNOLOGI KREATIVA MELALUI MEDIA TEKNOLOGI KOMUNIKASI "SLACK"

berhubungan dengan intruksi dan rasinal (Muhammad, 2015). Informasi yang diberikan oleh Porject Manager dari PT. Exaditama Teknologi Kreativa bisa berupa informasi tata kerja atau peraturan saat dan dalam bekerja untuk memberikan kelancaran dalam proses pekerjaan. Contoh peraturan yang sederhana di PT. Exaditama Teknologi Kreativa yaitu mengaktifkan fiture notifikasi pada saat membuka aplikasi slack, agar pimpinan tau dan anggota lainnya mengetahui bahwa karywan tersbut sedang dalam online atau sedang dalam bekerja.
Balikan, balikan merupakan pesan informasi mengenai ketepatan individu dalam melakukan pekerjaannya (Muhammad, 2015). Jika dilihat dari feedback pesan atau pekerjaan dari karyawan kepada pimpinan PT. Exaditama Teknologi Kreativa terdapat ketepatan penyampaian tugas yang cukup baik tetapi ada juga dalam pemberian tugas kerja kepada pimpinan terdapat kendala atau hambatan dan menjadikan feedback pesan kurang baik.

Selain itu juga di PT. Exaditama Teknologi Kreativa menjalankan jaringan komunikasi upward, komunikasi ini bermakna penyampaian pesan dari karyawan atau bawahan kepada pimpinan yang pesannya berisi pertanyaan, penyelesaian tugas kerja, atau bisa juga solusi kepada pimpinan. Terdapat fungsi dari jaringan komunikasi upward (Muhammad, 2015) sebagai berikut :

Dengan adanya komunikasi
upward pimpinan memperoleh
informasi yang disampaikan oleh
bawahan. Seperti yang diterapkan di


Jurnal Teknologi Informasi dan Komunikasi, ISSN : 2087-0868, Volume 11, Nomor 2, September 2020, POLA KOMUNIKASI ORGANISASI KARYAWAN START UP PT.EXADITAMA TEKNOLOGI KREATIVA MELALUI MEDIA TEKNOLOGI KOMUNIKASI "SLACK"

PT. Exaditama Teknologi Kreativa karyawan memberikan informasi berupa hal pesan yang berkaitan dengan pekerjaan. Contohnya seperti memberikan informasi bahwa terdpat masalah dalam sistematik pengerjaannya.

Jaringan komunikasi upward juga memberikan hal yang cukup berharga kepada pimpinan. Karyawan di PT. Exaditama Teknologi Kreativa selalu memberikan infromasi yang berharga kepada pimpinan, sperti ilmu atau pengetahuan yang dapat di sharing dan dapat diterapkan bersama dengan mempelajarinya.

Jaringan komunikasi upward membantu karyawan dapat mengatasi permasalahan yang telah dihadapinya mengenai pekerjaan. Seperti karyawan di PT. Exaditama Teknologi Kreativa terbiasa menghadapi permasalahan dan saat permasalahan itu tidak bisa dikerjakan dan tidak ada solusi, karyawan biasanya menginformasikan kepada pimpinan.
Menurut Pace dan Faules pada dasarnya tiap organisasi menggunakan proses berurutan umum untuk mendapatkan dan menyampaikan informasi ke semua anggota (Saleh, 2016). Begitu pula yang terjadi di PT. Exaditama Teknologi Kreativa terdapat proses penyampaian pesan dari pimpinan terhadap karyawan dengan beberapa pola komunikasi diantaranya :

Pola komunikasi roda,yakni pola yang mengarahkan seluruh informasi kepada individu yang menduduki posisi sentral. Orang yang berada dalam posisi sentral memperoleh kontak dan informasi memecahkan masalah dengan saran dan persetujuan dari anggota yang lainnya (Saleh, 2016). Pimpinan atau Porject Manager dari PT. Exaditama Teknologi Kreativa memberikan pesan informasi yang berhubungan dengan tugas kerja kepada setiap karyawanya melalui aplikasi slack. Pimpinan memberikan tugasnya menyeluruh kepada karyawan dari sebuah media komunikasi dan hingga secara beratatp muka langsung sehingga seluruh karyawan mendapatkan tugas kerjanya masing 
Jurnal Teknologi Informasi dan Komunikasi, ISSN : 2087-0868, Volume 11, Nomor 2, September 2020, POLA KOMUNIKASI ORGANISASI KARYAWAN START UP PT.EXADITAMA TEKNOLOGI KREATIVA MELALUI MEDIA TEKNOLOGI KOMUNIKASI "SLACK"

- masing. Terdapat sebuah channel atau sebuah grup dalam aplikasi slack yang bertujuan untuk pemberian tugas melalui media komunikasi dan channel berisi beberapa anggota karyawan yang bersangkutan dengan tugas kerja yang diberikan pimpinan. Selain untuk sarana pemebrian tugas kerja, channel juga dapat dipergunakan untuk pemberian tugas kerja yang telah diselesaikan karywan atau bisa juga menjadi wadah diskusi dengan pimpinan untuk menyelesaikan permasalahan .

Pola komunikasi seluruh saluran, seperti yang telah dipaparkan dalam bab sebelumnya, menjelasakn setiap anggota organisasi dapat berkomunikasi dengan seluruh anggota organisasi satu sama lain secara aktif, dimana setiap anggota organisasi tidak ada yang berperan menjadi pimpinan dan setiap anggota juga dapat memberikan kontribusi terhadap hal yang sednag dipermasalahkannya. dalam proses penyelesaian masalah dalam pekerjaan, karyawan dan pimpinan PT. Exaditama Teknologi Kreativa membuat sebuah channel dalam aplikasi slack untuk mendisukusikan dan memberikan pendapat atau solusi baik itu dari pimpinan Porject Manager kepada karyawan, atau sebaliknya dari karyawan kepada Porject Manager. Dari hasil penelitian bahwa dalam percakapan di channel aplikasi slack tidak serta merta berisi percakapan mengenai pekerjaan, tetapi terdapat juga percakapan yang berada diluar hubungan pekerjaan.

Dapat diartikan bahwa pola dari komunikasi di PT. Exaditama Teknologi Kreativa dengan jaringan komunikasi Downward terdapat pola komunikasi roda dan pola komunikasi seluruh saluran. Dimana pola komunikasi roda dengan jaringan Downward dan Upward terdapat hasil yang cukup jelas mengenai perintah, aturan, pemeberian tugas kerja, solusi dan infromasi dari pimpinan kepada karyawan melalui aplikasi slack, yang dimana pola tersbut terdapat beberapa tahap proses kerja diawali dari pemebrian tugas besar dari aplikasi Trello, kemudian diskusi 
Jurnal Teknologi Informasi dan Komunikasi, ISSN : 2087-0868, Volume 11, Nomor 2, September 2020, POLA KOMUNIKASI ORGANISASI KARYAWAN START UP PT.EXADITAMA TEKNOLOGI KREATIVA MELALUI MEDIA TEKNOLOGI KOMUNIKASI "SLACK"

mengneai pengerjaan tugas dengan daily scrum, lalu kemudian proses pemberian tugas kerja secara detail melalui aplikasi slack yang telah diatur oleh pimpinan. Selain itu juga terdapat pola komunikasi seluruh saluran dengan jaringan komunikasi Downward. Terdapat alur penyampaian pesan yang cukup kompleks di PT. Exaditama Teknologi Kreativa, dimana pimpinan tidak berperan menjadi pimpinan sebab dalam pola komunikasi seluruh saluran yang terdapat di PT. Exaditama Teknologi Kreativa karyawan dapat meberikan solusi kepada pimpinan secara langsung baik itu dalam ranah pekerjaan atau pun diluar pekerjaan.

\section{SIMPULAN}

Berdasarkan dari data yang telah didapat, maka peneliti menarik kesimpulan terdapat hasil jaringan komunikasi Upward dan Downward dengan pola komunikasi roda dan pola komunikasi seluruh saluran. Jaringan komunikasi Downward di PT. Exaditama Teknologi Kreativa memberikan pesan arahan, perintah, solusi, ide atau informasi yang berkaitan dengan pekerjaan. Jaringan komunikasi Upward karyawan di PT. Exaditama Teknologi Kreativa lebih memberikan pesan berisi solusi, pendapat serta keluhan jika terdapat hambatan. Pola komunikasi roda didalam PT. Exaditama Teknologi Kreativa menjelaskan bahwa semua arahan, perintah, dan tugas kerja terpusat dari pimpinan atau Project Manager kemudian diberikan kepada karyawan yang telah di kelompokan melalui aplikasi Slack dengan fitur channel. Pola komunikasi seluruh saluran didalam PT. Exaditama Teknologi Kreativa menggambarkan pesan yang berisi sebagai diskusi, pemberian solusi, atau pemberian informasi terhadap pimpinan dengan tidak dilihatnya status jabatan. Alur dari jaringan pesan komunikasi Downward dan Upward meliputi tahapan awal aplikasi Trello (Pemebrian judul tugas kerja besar), Metode Scrum (Diskusi memahami pola tugas kerja), aplikasi Slack (Seluruh alur pesan berisi tugas kerja, diskusi, informasi dll). 
Jurnal Teknologi Informasi dan Komunikasi, ISSN : 2087-0868, Volume 11, Nomor 2, September 2020, POLA KOMUNIKASI ORGANISASI KARYAWAN START UP PT.EXADITAMA TEKNOLOGI KREATIVA MELALUI MEDIA TEKNOLOGI KOMUNIKASI "SLACK"

\section{DAFTAR PUSTAKA}

DSResearch. (2020). Laporan DSResearch: Startup Report 2019. Maret. https://dailysocial.id/post/lapora n-startup-report-2019

Fadilla, I. (2020). Indonesia Menjadi Negara Ranking ke 5 Startup Terbanyak di 2019. Januari. https://www.kabaruang.com/202 0/01/indonesia-menjadi-negararanking-ke-5-startup-terbanyakdi-2019/

Indrawati. (2018). Metode Penelitian Kualitatif Manajemen dan Bisnis Konvergensi Teknologi Informasi dan Komunikasi (Rachmi (ed.)). Refika Aditama. Muhammad, A. (2015). Komunikasi Organisasi (Joni Raka (ed.)). Bumi Aksara.

Nabila, M. (2016). 3 Sikap Founder Startup Penyebab Pekerja Mengundurkan Diri. November. https://dailysocial.id/post/3sikap-founder-startuppenyebab-pekerjamengundurkan-diri

Nugrahani, F. (2014). Metode Penelitian Kualitatif dalam Penelitian Pendidikan Bahasa (p. 320).

Priambada, A. (2015). Tujuh Kesalahan Ini Dapat Membuat Startup Kehilangan Karyawan Terbaik. Juli. https://dailysocial.id/post/tujuhkesalahan-ini-dapat-membuatstartup-kehilangan-karyawanterbaik
Saleh, M. (2016). Komunikasi dalam Kepemimpinan Organisasi (W. Wiranata (ed.)). UB Press.

DSResearch. (2020). Laporan DSResearch: Startup Report 2019. Maret. https://dailysocial.id/post/laporanstartup-report-2019

Fadilla, I. (2020). Indonesia Menjadi Negara Ranking ke 5 Startup Terbanyak di 2019. Januari. https://www.kabaruang.com/2020/ 01/indonesia-menjadi-negararanking-ke-5-startup-terbanyak-di2019/

Indrawati. (2018). Metode Penelitian Kualitatif Manajemen dan Bisnis Konvergensi Teknologi Informasi dan Komunikasi (Rachmi (ed.)). Refika Aditama.

Muhammad, A. (2015). Komunikasi Organisasi (Joni Raka (ed.)). Bumi Aksara.

Nabila, M. (2016). 3 Sikap Founder Startup Penyebab Pekerja Mengundurkan Diri. November. https://dailysocial.id/post/3-sikapfounder-startup-penyebab-pekerjamengundurkan-diri

Nugrahani, F. (2014). Metode Penelitian Kualitatif dalam Penelitian Pendidikan Bahasa (p. 320).

Priambada, A. (2015). Tujuh Kesalahan Ini Dapat Membuat Startup Kehilangan Karyawan Terbaik. Juli.

https://dailysocial.id/post/tujuhkesalahan-ini-dapat-membuatstartup-kehilangan-karyawanterbaik

Saleh, M. (2016). Komunikasi dalam Kepemimpinan Organisasi (W. Wiranata (ed.)). UB Press. 
